\title{
JAK inhibitors for refractory lymphoma
}

\section{Hiroshi Kimura}

News on: STAT3 is constitutively activated in chronic active Epstein-Barr virus infection and can be a therapeutic target by Onozawa et al. Oncotarget. 2018; 9:31077-31089. https://doi.org/10.18632/oncotarget.25780

Epstein-Barr virus (EBV), which belongs to the gammaherpesvirus subfamily, is a ubiquitous tumor virus. EBV infects $\mathrm{B}$ cells via $\mathrm{CD} 21$ and is associated with a variety of B-cell neoplasms such as Burkitt lymphoma, EBV-positive diffuse large B-cell lymphoma, and posttransplant lymphoproliferative disorders [1]. EBV also infects T and NK cells and is associated with extranodal NK/T cell lymphoma-nasal type, aggressive NK-cell leukaemia, and EBV-positive T-cell and NK-cell lymphoproliferative diseases of childhood (EBV+ T/NK LPD) $[1,2]$.

Chronic active EBV infection (CAEBV), which is defined as an EBV+ T/NK LPD in the 2017 WHO classification [3], is characterised by persistent EBV infection in $\mathrm{T} / \mathrm{NK}$ cells and occasional transformation to peripheral lymphoma of $\mathrm{T} / \mathrm{NK}$-cell lineage cells $[2,4,5]$. The disease has an inflammatory aspect, as hypercytokinaemia is a common feature [6]. CAEBV is a rare but intractable disease with a poor prognosis. Compared with EBV+ B-cell neoplasms, which can be treated with rituximab-containing regimens, the optimum treatment strategy for CAEBV has not yet been established.

In this issue of Oncotarget, Onozawa et al. report that signal transducers and activators of transcription (STAT) 3 is constitutively active in both EBV+ T/NK cell lines and peripheral blood mononuclear cells from CAEBV patients [7]. They also show that ruxolitinib, an inhibitor of Janus kinase (JAK) $1 / 2$, suppresses not only the viability of EBV-infected T/NK cells but also their production of inflammatory cytokines. From these results, they conclude that STAT3 could be a therapeutic target for CAEBV.

STAT3 is an important signalling mediator and is constitutively activated in a variety of tumours, including lymphomas. Therefore, this mediator has been investigated as a target for the treatment of many types of cancer. Interestingly, STAT3 is activated in most EBVassociated hematological and epithelial malignancies. Latent membrane protein (LMP) 1 is an oncoprotein encoded by EBV, and constitutively activates the NF- $\kappa \mathrm{B}$, $\mathrm{PI} 3 \mathrm{~K} / \mathrm{AKT}$, and JNK pathways [1]. LMP1 specifically interacts with JAK and activates STAT proteins, including STAT3. Moreover, activation of the JAK/STAT pathway promotes the expression of LMP1 [8]. Onozawa et al. also demonstrate that ruxolitinib inhibits the phosphorylation of constitutively active STAT3 and induces apoptosis in an EBV-positive T-cell line. We recently reported that tofacinib, a JAK3-selective inhibitor, induces G1 cellcycle arrest and inhibits the growth of EBV-positive T/ NK lymphoma cells, in which the JAK/STAT pathway is activated [9]. Whether such constitutive activation of the JAK/STAT pathway is mediated by LMP1 is of great interest, although confirmation of this would require silencing of the LMP1 gene, which is difficult, particularly in $\mathrm{T} / \mathrm{NK}$ cell lines.

Novel approaches involving molecular-targeted therapies are needed to establish the optimum treatment strategy for CAEBV. At present the only curative therapy is hematopoietic stem cell transplantation, but this has a high incidence of complications [4, 5]. JAK inhibitors such as ruxolitinib and tofacinib are promising candidates for this purpose, as they target the EBV-driven pathway. More importantly, these drugs are approved and in use for other diseases (ruxolitinib for myelofibrosis and polycythemia vera; tofacinib for rheumatoid arthritis); therefore, evidence of their safety is abundant. We hope that incorporation of JAK inhibitors in the treatment regimen will improve the prognosis of CAEBV, although further extensive ex vivo and in vivo studies are necessary to clarify the efficacy of these drugs.

Hiroshi Kimura: Department of Virology, Nagoya University Graduate School of Medicine, Tsurumai-cho, Showa-Ku, Nagoya, Japan

Correspondence to: Hiroshi Kimura, email hkimura@med.nagoya-u.ac.jp

Keywords: EBV; CAEBV; STAT3; ruxolitinib

Received: July 11, 2018

Published: August 31, 2018

\section{REFERENCES}

1. Longnecker R, et al. Fields Virology. (Philadelphia: Wolters Kluwer Health/Lippincott Williams \& Willkins). 2013; pp. 1898-959.

2. Cohen JI, et al. Ann Oncol. 2009; 20:1472-82. https://doi.org/10.1093/annonc/mdp064.

3. Quintanilla-Martinez L, et al. WHO Classification of Tumours of Haematopoietic and Lymphoid Tissues, Volume 2. (Lyon: IARC). 2017; pp. 355-62. 
4. Kimura H, et al. Blood. 2012; 119:673-86. https://doi.org/10.1182/blood-2011-10-381921.

5. Kimura H, et al. Front Immunol. 2017; 8:1867. https://doi.org/10.3389/fimmu.2017.01867.

6. Kimura H, et al. Rev Med Virol. 2006; 16:251-61.

7. Onozawa E, et al. Oncotarget. 2018; 9:31077-31089. https://doi.org/10.18632/oncotarget.25780.

8. Chen H, et al. J Virol. 2003; 77:4139-48.

9. Ando S, et al. Oncotarget. 2016; 7:76793-805. https://doi.org/10.18632/oncotarget.12529.

Copyright: Kimura et al. This is an open-access article distributed under the terms of the Creative Commons Attribution License 3.0 (CC BY 3.0), which permits unrestricted use, distribution, and reproduction in any medium, provided the original author and source are credited. 